\title{
Natural Convection and Radiation Heat Loss from Open Cavities of Different Shapes and Sizes Used with Dish Concentrator
}

\author{
R. D. Jilte ${ }^{1}$, S. B. Kedare ${ }^{1} \&$ J. K. Nayak ${ }^{1}$ \\ ${ }^{1}$ Department of Energy Science and Engineering, Indian Institute of Technology Bombay, India \\ Correspondence: J. K Nayak, Department of Energy Science and Engineering, Indian Institute of Technology \\ Bombay, India. Tel: 91-22-257-677-881. E-mail: jknayak@iitb.ac.in
}

Received: December 14, 2012

Accepted: January 7, 2013 Online Published: January 20, 2013

doi:10.5539/mer.v3n1p25

URL: http://dx.doi.org/10.5539/mer.v3n1p25

\begin{abstract}
Numerical three dimensional studies of the combined natural convection and radiation heat loss from downward facing open cavity receiver of different shapes is carried out in this paper. The investigation is undertaken in two categories: same inner heat transfer area and aperture area (case I) and same aspect ratio and aperture area (case II). These studies are carried out for five isothermal wall temperatures (523 to $923 \mathrm{~K}$ in steps of 100K). The effect of inclination is studied for seven inclinations from $0^{\circ}$ (cavity aperture facing sideways) to $90^{\circ}$ (cavity aperture facing down), in steps of $15^{\circ}$. The cavity shapes used are: cylindrical, conical (frustum of a cone), cone-cylindrical (combination of frustum of cone and cylindrical shape), dome-cylindrical (combination of hemispherical and cylindrical shape), hetro-conical, reverse-conical (frustum of a cone in the reverse orientation) and spherical. For both cases, conical cavity yields the lowest convective loss among the cavities investigated whereas spherical cavity results in the highest convective loss. Convective heat loss from cavities of different shapes and sizes are characterized by using different internal zone areas of the cavity $\left(\mathrm{A}_{\mathrm{cw}}, \mathrm{A}_{\mathrm{cz}}, \mathrm{A}_{\mathrm{cb}}\right.$ and $\left.\mathrm{A}_{\mathrm{w}}\right) . \mathrm{A}_{\mathrm{cb}}$ is found to be better parameter for characterization of the convective heat loss. Nusselt number correlation is developed using convective zone area $\left(\mathrm{A}_{\mathrm{cb}}\right)$. It correlates $91 \%$ of data within $\pm 11 \%$ deviation, $99 \%$ of data within $\pm 16 \%$ deviation. Radiative losses $\left(\mathrm{Q}_{\mathrm{rad}}\right)$ have been determined numerically from cavities of both cases. The ratio of $\mathrm{Q}_{\mathrm{rad}} / \mathrm{A}_{\mathrm{ap}}$ is found to be more or less constant (variation within 5\%) for all types of cavities and for $0 \leq \varepsilon \leq 1$. Thus radiative loss is dependent on aperture area and effective emissivity of cavity rather than the shape of the cavity. Further, it also matches well with the analytical formula based on effective emissivity.
\end{abstract}

Keywords: paraboloid dish-receiver systems, cavity receivers, natural convection heat loss, radiative heat loss, nusselt number correlation

\section{Introduction}

The concentrating solar technology has the potential to be used for supplying industrial process heat as well for generating power. The parabolic dish-receiver assembly is one such promising system. It usually consists of a reflector in the form of a dish with downward facing receiver at the focus of the dish. Generally, a cavity receiver is used since it can maximize the absorption of the concentrated flux and minimize heat losses (Harris \& Lenz, 1984). The heat losses include convective and radiative losses through the opening of the cavity and conduction through the supporting structure and through the insulation used behind the cavity surfaces. Generally, the loss due to conduction is quite small and can easily be calculated.

A number of studies on convection and radiation from cavities have been reported in the literature. These can be classified into two groups, viz. open cavity and solar cavity. The former refers to an enclosure (with one side open to ambient) having no arrangement for flow of working fluid through the receiver. On the other hand, solar cavity refers to an enclosure (with one side open to ambient) having flow arrangement for the working fluid (receiver walls are in the form of tubes).

The investigations on convective losses from open cavities (cubical, rectangular and square) have been carried out by a number of research groups. In these investigations, the cavity walls are either uniformly heated or one wall is heated and others are maintained at adiabatic conditions. A few studies have also been reported on the combined effect of natural convection and radiation in open cavities. In these studies, inner walls of the cavity were maintained at different temperatures. Since temperature differentials exist on the inner walls of the cavity, the radiation heat transfer from these surfaces alter the basic flow pattern thus modifying the convection and 
radiative losses. Consequently, the accurate prediction of the flow and thermal field necessitates the consideration of combined convection and radiation.

The literature reports investigations on various types of solar cavities. The present study focuses on the cavities meant for parabolic dish concentrator. These are: cylindrical (D'Utruy, Blay, \& Coteytaux, 1978; Umarov et al., 1983; Harris \& Lenz, 1985; Taumoefolau \& Lovegrove, 2002; Paitoonsurikarn \& Lovegrove, 2002, 2003, 2006; Paitoonsurikarn, Taumoefolau, \& Lovegrove, 2004; Taumoefolau, Paittonsurikarn, Hughes, \& Lovegrove, 2004; Melchior, 1989), cylindrical with wind skirt (Paitoonsurikarn \& Lovegrove, 2002, 2004; Prakash, Kedare, \& Nayak, 2009, 2010), conical and dome-cylindrical (Ryu \& Seo, 2000; Seo, Ryu, \& Kang, 2003), conical (Harris \& Lenz, 1985), cylindrical with conical frustum (Kugath, Drenker, \& Koenig, 1779; Lezhebokov, Sokolova, \& Trukhov, 1986; Stine \& McDonald, 1988, 1989; Ma, 1993; McDonald, 1995), Spherical (Harris \& Lenz, 1985; Leibfried \& Ortjohann, 1995; Sendhilkumar \& Reddy, 2008), conical with annular aperture plate (Paitoonsurikarn \& Lovegrove, 2002, 2004; Perez-Rabago, Marcos, Romero, \& Estrada, 2008), hemisphere with annular aperture plate (Sendhilkumar \& Reddy, 2007, 2008; Reddy \& Sendhilkumar, 2008, 2009), hetro-conical (William, 1980; Harris \& Lenz, 1985) and elliptical (Harris \& Lenz, 1985). The type of investigation includes experimental and/or numerical estimation of convective loss and/or total loss. The wall conditions used were either isothermal with flat walls (without arrangement for heat absorbing fluid passage) or with it.

In these studies, in addition to different shapes, the geometrical dimensions and operating temperatures vary from one investigation to another; for example, the aperture area of the cavity, the depth of cavity and inner wall area of the cavity are different from one to another. Consequently, the reported numerical as well as experimental results cannot be compared. McDonald (1995) has carried out experiment on conical-frustum cylindrical cavity at operating temperature of $148{ }^{\circ} \mathrm{C}$ to $315^{\circ} \mathrm{C}$. He has compared experimental data with heat loss correlations developed by Le Quere et al. (1981), Clausing (1983) and Siebers and Kraabel (1984). He reported that the correlations of Le Quere et al. (1981) and that of Siebers and Kraabel (1984) underestimate heat loss compared to the experimental data. This mismatch may be attributed to the use of cavity internal surface area, $A_{w}$ for developing the correlation. For different shapes, the $A_{w}$ values are different and hence, the heat loss predicted can be different. The correlation of Clausing (1983) is comparatively closer to the experimental data due to the use of convective zone area rather than $A_{w}$. This underlines the need of identification of relevant cavity area contributing to convective loss. Similar observations are applicable to the deviations of the experimental data of Taumoefolau et al. (2004) for cylindrical cavity from the correlations of Stine and McDonald (1989) and Clausing (1983).

It is therefore desirable to compare cavities of different shapes and sizes on a common basis. This comparison should be over a wide temperature range covering process heat to power generation ( 523 to $923 \mathrm{~K}$ ). Further, the development of generalized correlation for predicting convective heat loss from cavities of shapes and sizes would be desirable.

\section{Types of the Cavities Investigated}

The current work deals with cavity receivers which have been reported in the literature for parabolic dish concentrators. These are cylindrical, conical (frustum of a cone), cone-cylindrical shape (combination of frustum of cone and cylindrical shape), dome-cylindrical shape (combination of hemispherical and cylindrical shape), hetro-conical shape and Spherical. In addition to these shapes, reverse-conical shape (frustum of a cone in the reverse orientation) is also included for completeness of the study on conical shape. These are shown in Figure 1. The applications envisaged are process heat in the form of steam, pressurized hot water, hot oil as well as supplementing heat to the existing power plant, typically operating for $250{ }^{\circ} \mathrm{C}$ to $650{ }^{\circ} \mathrm{C}$ (Paitoonsurikarn \& Lovegrove, 2002). The receivers generating steam generally operate at constant fluid temperature and hence isothermal wall conditions are realized (Clique, www.clique.in).

While comparing these different shapes, their aperture diameter is taken to be same. This is due to the fact that for a given paraboloid dish receiver systems, the size of the optical focus is fixed and is typically of 0.4 to $0.5 \mathrm{~m}$ diameter for dishes used for industrial process heat (www.clique.in; Sardeshpande, Chandak, \& Pillai, 2011; Chandak, Somani, \& Dubey, 2009). In the present study, this aperture diameter is taken as $0.5 \mathrm{~m}$. Size of the receiver used in the current work is similar to the receiver used in a parabolic dish-receiver system installed at Mahanand dairy, Latur, Maharashtra, India for supplying process heat (Bhosale, Kedare, \& Nayak, 2008). 


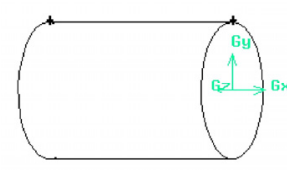

(a) Cylindrical

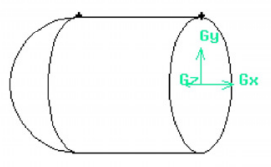

(d) Dome-cylindrical

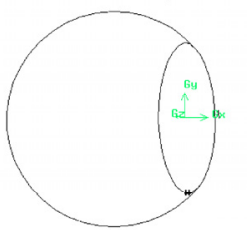

(g) Spherical

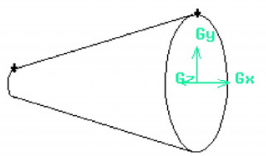

(b) Conical

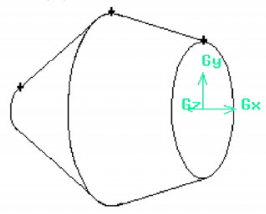

(e) Hetro-conical

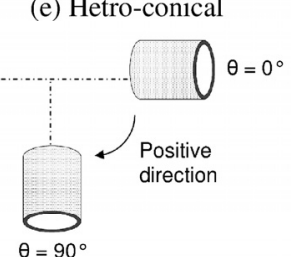

(h) Sign convention used for inclination of cavity

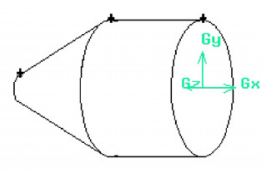

(c) Cone-cylindrical

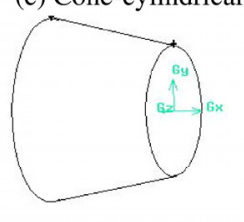

(f) Reverse-conical

Figure 1. Types of the cavities investigated

The aspect ratio (AR) is defined as ratio of the length of cavity $\left(\mathrm{L}_{\mathrm{cav}}\right)$ to the aperture diameter $\left(\mathrm{D}_{\mathrm{ap}}\right)$. These terms and sign conventions used for inclinations are shown in Figure 1(h).

Cylindrical cavity is taken as the base cavity with dimension of $\mathrm{D}_{\mathrm{ap}}=0.5 \mathrm{~m}, \mathrm{AR}=1.5, \mathrm{~L}_{\mathrm{cav}}=0.75 \mathrm{~m}$ and cavity inner wall area $\left(\mathrm{A}_{\mathrm{w}}\right)=1.374 \mathrm{~m}^{2}$ for various comparisons. The effect of shape on total heat loss is studied in two ways. In case I, with the aperture diameter fixed $(0.5 \mathrm{~m})$, the length of cavity is varied to get constant inner wall area equal to $1.374 \mathrm{~m}^{2}$ for all shapes. This will result in different values of AR. In case II, with aperture diameter fixed $(0.5 \mathrm{~m})$ and length of the cavity is kept constant to get constant AR equal to 1.5, allowing the inner wall area to vary. Table 1 presents details of these two cases.

Table 1. Details of cavities investigated

\begin{tabular}{lcccc}
\hline \multicolumn{1}{c}{ Cavity shape } & \multicolumn{2}{c}{ Case I } & \multicolumn{2}{c}{ Case II } \\
& $\mathrm{A}_{\mathrm{w}}\left(\mathrm{m}^{2}\right)$ & $\mathrm{AR}$ & $\mathrm{AR}$ & $\mathrm{A}_{\mathrm{w}}\left(\mathrm{m}^{2}\right)$ \\
\hline Cylindrical & & 1.5 & & 1.374 \\
Conical & & 2.06 & & 0.739 \\
Cone-cylindrical & 1.374 & 1.88 & 1.5 & 0.989 \\
Dome-cylindrical & & 1.74 & & 1.178 \\
Hetro-conical & & 1.5 & & 1.374 \\
Reverse-conical & & 1.03 & & 1.934 \\
Spherical & & 1.22 & & 1.967 \\
\hline
\end{tabular}

\section{Numerical Analysis}

The CFD Software Package 'Fluent 6.3.26' (2006) was employed to carry out the three dimensional simulation of the cavity receiver. For each cavity (Table 1), three dimensional model was created using Gambit tool of CFD software package 'Fluent 6.3.26'. In reality, the receiver is surrounded by an infinite atmosphere having temperature equal to ambient air temperature. To model this condition in the numerical work, the flow domain is chosen such that the receiver is placed centrally in a large cylindrical enclosure. This is to ensure that the air flow within the cavity is unaffected. The 3-D receiver model is analyzed for different inclinations by adjusting the gravity vector accordingly (Taumoefolau et al., 2004).

The flow and heat transfer simulation is based on the simultaneous solution of a system of equations describing the conservation of mass, momentum and energy. These can be expressed for an incompressible fluid, as (Jiji, 2006): 


$$
\begin{gathered}
\frac{\partial}{\partial x}(\rho u)+\frac{\partial}{\partial x}(\rho v)+\frac{\partial}{\partial x}(\rho w)=0 \\
\rho\left[u \frac{\partial u}{\partial x}+v \frac{\partial u}{\partial y}+w \frac{\partial u}{\partial z}\right]=\rho g_{x}-\frac{\partial p}{\partial x}+\mu\left[\frac{\partial^{2} u}{\partial x^{2}}+\frac{\partial^{2} u}{\partial y^{2}}+\frac{\partial^{2} u}{\partial z^{2}}\right] \\
\rho\left[u \frac{\partial v}{\partial x}+v \frac{\partial v}{\partial y}+w \frac{\partial v}{\partial z}\right]=\rho g_{y}-\frac{\partial p}{\partial y}+\mu\left[\frac{\partial^{2} v}{\partial x^{2}}+\frac{\partial^{2} v}{\partial y^{2}}+\frac{\partial^{2} v}{\partial z^{2}}\right] \\
\rho\left[u \frac{\partial w}{\partial x}+v \frac{\partial w}{\partial y}+w \frac{\partial w}{\partial z}\right]=\rho g_{z}-\frac{\partial p}{\partial z}+\mu\left[\frac{\partial^{2} w}{\partial x^{2}}+\frac{\partial^{2} w}{\partial y^{2}}+\frac{\partial^{2} w}{\partial z^{2}}\right] \\
\rho C_{p}\left[u \frac{\partial T}{\partial x}+v \frac{\partial T}{\partial y}+w \frac{\partial T}{\partial z}\right]=k\left[\frac{\partial^{2} T}{\partial x^{2}}+\frac{\partial^{2} T}{\partial y^{2}}+\frac{\partial^{2} T}{\partial z^{2}}\right]
\end{gathered}
$$

Surface-to-Surface (S2S) radiation model is used for modeling the enclosure radiative transfer without participating media to account for the radiation exchange in an internal surface of the cavity receiver (Fluent 6.3 user guide, 2006; Reddy \& Sendhilkumar, 2008). In the S2S radiation model, the surfaces are taken as gray and diffuse. The energy exchange between two surfaces depends on their size, separation distance, and orientation. The influences of these parameters are accounted by a view factor (Fluent 6.3 user guide, 2006). The rate of radiative heat loss from the $i^{\text {th }}$ surface of the enclosure can be written as

$$
\mathrm{Q}_{\mathrm{rad}, \mathrm{i}}=\frac{\mathrm{A}_{\mathrm{i}} \varepsilon_{\mathrm{i}}}{1-\varepsilon_{\mathrm{i}}}\left(\sigma \mathrm{T}_{\mathrm{i}}{ }^{4}-\mathrm{J}_{\mathrm{i}}\right)
$$

where $\mathrm{J}_{\mathrm{i}}$ is given by

$$
\mathrm{J}_{\mathrm{i}}=\left(1-\varepsilon_{\mathrm{i}}\right) \underset{\mathrm{j}=1}{\mathrm{~N}} \mathrm{~F}_{\mathrm{ij}} \mathrm{J}_{\mathrm{j}}+\varepsilon_{\mathrm{i}} \sigma \mathrm{T}_{\mathrm{i}}^{4}
$$

The rate of total radiative heat loss is calculated by summing $Q_{\text {rad,i }}$ over all surfaces.

An isothermal boundary condition was applied to the cavity wall whereas the outer walls of the receiver were adiabatic since the wall is insulated. Pressure inlet boundary condition was applied to the outer domain. Since the temperature range of the current work is 523-923 K, the Boussinesq approximation is not valid. This is because in this temperature range, the product of the coefficient of thermal expansion of air and temperature difference between cavity wall and air is found to be in the range of $0.742-2.075$. These values are much higher than 0.1 for Boussinesq approximation to be applicable (Gray \& Giorgini, 1976). Hence non-Boussinesq approximation is used in the current work, i.e. the ideal gas characteristics are used for cavity air. The solutions are obtained by solving the continuity, momentum and energy equation simultaneously. The semi-implicit pressure linked equation (SIMPLE) scheme of the FLUENT software is used. The SIMPLE algorithm involves a pressure-velocity coupling and is used for steady state simulation in the current work. The standard k- $\varepsilon$ model is used in the present work. It is most widely-used engineering turbulence model for industrial applications. It is robust and reasonable accurate and contains sub-models for buoyancy (Fluent 6.3 user guide, 2006). The momentum and energy solution controls are of the second order upwind type. The convergence criteria for the residuals of continuity and the velocity equations are of the order of $10^{-3}$ while for the energy equation it is $10^{-6}$. The convergence is judged by examining residual levels and also by monitoring relevant integrated quantities such as heat transfer coefficient. The solutions are obtained once the convergence criteria are satisfied. Grid independent study was carried out for each shape and results are presented in Table 2.

The current numerical model considers adiabatic condition on the outer surface of the cavity with negligible wall thickness; consequently the conduction loss is taken as zero. The model calculates the value of the total heat transfer rate $\left(\mathrm{Q}_{\text {tot, } \mathrm{i}}=\mathrm{Q}_{\mathrm{conv}, \mathrm{i}}+\mathrm{Q}_{\mathrm{rad}, \mathrm{i}}\right)$ as well as radiative heat transfer rate $\left(\mathrm{Q}_{\mathrm{rad}, \mathrm{i}}\right)$ for each surface (say $\mathrm{i}^{\text {th }}$ surface $)$ of a cavity. In order to estimate the total heat loss $\left(\mathrm{Q}_{\mathrm{tot}}\right)$ of the cavity, loss terms of each surface $\left(\mathrm{Q}_{\mathrm{tot}, \mathrm{i}}\right)$ are added. Similarly, $\mathrm{Q}_{\mathrm{rad}}$ is calculated by summing the radiation heat transfer rate for all surfaces. The values of $\mathrm{Q}_{\mathrm{conv}}$ are then calculated by subtracting $\mathrm{Q}_{\mathrm{rad}}$ from $\mathrm{Q}_{\mathrm{tot}}$ over the faces. 
This modeled cavity is surrounded by a cylindrical enclosure (domain). Sensitivity study of outer domain has been carried out to ascertain the size of outer domain by taking the example of cylindrical cavity $\left(\mathrm{D}_{\mathrm{ap}}=0.5 \mathrm{~m}\right.$, $\left.\mathrm{L}_{\text {cav }}=0.75 \mathrm{~m}\right)$ with wall temperature $\left(\mathrm{T}_{\mathrm{w}}\right)$ as $723 \mathrm{~K}$. The size of domain is varied from 5 to 15 times that of cavity aperture diameter and the results are presented in Table 3. It is seen that the percentage change in convective loss for a domain of $15 \mathrm{D}_{\mathrm{ap}}$ is very small $(0.47 \%)$ compared to that of $10 \mathrm{D}_{\mathrm{ap}}$. Therefore cylindrical domain having diameter and length equal to $15 \mathrm{D}_{\mathrm{ap}}$ is chosen in the present numerical work.

Table 2. Grid independent study

\begin{tabular}{|c|c|c|c|c|c|c|c|}
\hline \multicolumn{4}{|c|}{ Case I } & \multicolumn{4}{|c|}{ Case II } \\
\hline & $\begin{array}{l}\text { No. of } \\
\text { elements } \\
\text { in mesh }\end{array}$ & $\begin{array}{c}Q_{\text {conv }} \\
\text { (W) }\end{array}$ & $\begin{array}{c}\% \\
\text { change }\end{array}$ & & $\begin{array}{l}\text { No. of } \\
\text { elements } \\
\text { in mesh }\end{array}$ & $\mathrm{Q}_{\text {conv }}(\mathrm{W})$ & $\begin{array}{c}\% \\
\text { change }\end{array}$ \\
\hline \multirow[t]{3}{*}{ Cylindrical } & 631100 & 2031.03 & & & & & \\
\hline & 483465 & 2028.04 & 0.15 & & & & \\
\hline & 265367 & 1857.39 & 8.55 & & & & \\
\hline \multirow[t]{3}{*}{ Conical } & 630720 & 1953.26 & & Conical & 479786 & 1143.64 & \\
\hline & 479296 & 1942.21 & 0.57 & & 392494 & 1130.00 & 1.19 \\
\hline & 232197 & 1799.42 & 7.88 & & 176661 & 991.90 & 13.27 \\
\hline \multirow[t]{3}{*}{ Cone-cylindrical } & 555424 & 2021.95 & & Cone-cylindrical & 555424 & 1567.59 & \\
\hline & 479809 & 2013.11 & 0.44 & & 433177 & 1523.00 & 2.84 \\
\hline & 233154 & 1854.9 & 8.26 & & 199901 & 1419.40 & 9.45 \\
\hline \multirow[t]{3}{*}{ Dome-cylindrical } & 651469 & 2040.76 & & Dome-cylindrical & 599829 & 1802.02 & \\
\hline & 489640 & 2033.41 & 0.36 & & 458934 & 1789.18 & 0.71 \\
\hline & 236912 & 1864.52 & 8.64 & & 218538 & 1648.431 & 8.52 \\
\hline \multirow[t]{3}{*}{ Hetro-conical } & 620282 & 2019.57 & & & & & \\
\hline & 480770 & 2005.00 & 0.72 & & & & \\
\hline & 232268 & 1792.31 & 11.25 & & & & \\
\hline \multirow[t]{3}{*}{ Reverse-conical } & 612967 & 2002.11 & & Reverse-conical & 756290 & 2614.08 & \\
\hline & 477195 & 1983.00 & 0.95 & & 562161 & 2601.15 & 0.49 \\
\hline & 230428 & 1811.75 & 9.51 & & 280277 & 2388.66 & 8.62 \\
\hline \multirow[t]{3}{*}{ Spherical } & 631100 & 2127.25 & & Spherical & 868068 & 2646.05 & \\
\hline & 478183 & 2116.00 & 0.53 & & 652841 & 2632.31 & 0.52 \\
\hline & 226056 & 1952.52 & 8.21 & & 278395 & 2421.31 & 8.49 \\
\hline
\end{tabular}

Table 3. Sensitivity study of outer domain

\begin{tabular}{lcc}
\hline \multirow{2}{*}{ Size of outer domain } & \multicolumn{2}{c}{ Numerical results } \\
\cline { 2 - 3 } & Qonv $(\mathrm{W})$ & \% change \\
\hline 5 times $\mathrm{D}_{\mathrm{ap}}$ & 3994 & - \\
10 times $\mathrm{D}_{\mathrm{ap}}$ & 4065 & 1.78 \\
15 times $\mathrm{D}_{\mathrm{ap}}$ & 4084 & 0.48 \\
\hline
\end{tabular}

In order to validate the numerical scheme, calculations have been carried out for convective heat loss of a cylindrical open cavity. The cavity walls are considered to be at a constant temperature. The results of calculations are compared with the experimental data of convective loss measurements reported by Taumoefolau et al. (2004) in Figure 2. It is observed that, the numerical results agree reasonably well with the experimental data.

Similarly for validating the numerical scheme used for estimating radiative heat loss, the experimental work of spherical cavity reported by Leibfried and Ortjohann (1995) has been considered. Figure 3 presents the comparison of experimental data with numerical results. It is observed that, the numerical results agree reasonably well with the experimental data. 


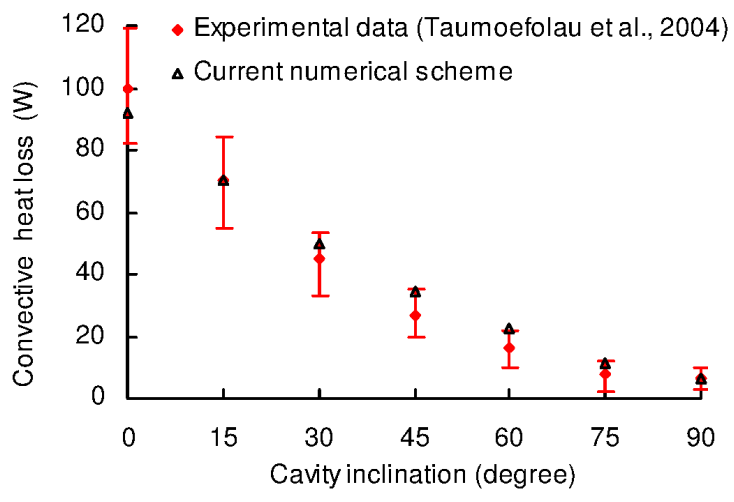

Figure 2. Comparison with experimental data of Taumoefolau et al. (2004)

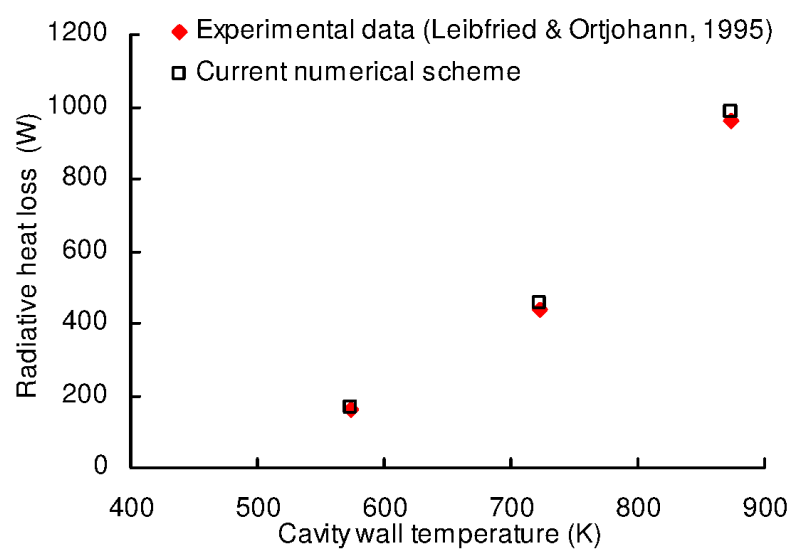

Figure 3. Comparison of numerical results of radiative heat loss with experimental data

\section{Results and Discussion}

The combined study of convective and radiative heat loss has been carried out for different cavities. Comparison among different shapes and sizes are carried out by evaluating heat loss through aperture opening.

\subsection{Convective Heat Loss}

The convective heat losses $\left(\mathrm{Q}_{\text {conv }}\right)$ from different cavities under different temperature conditions $\left(\mathrm{T}_{\mathrm{w}}\right)$ and inclinations $(\theta)$ have been calculated. A typical set of results for cylindrical cavity (base cavity) is shown in Figure 4 for various inclinations.

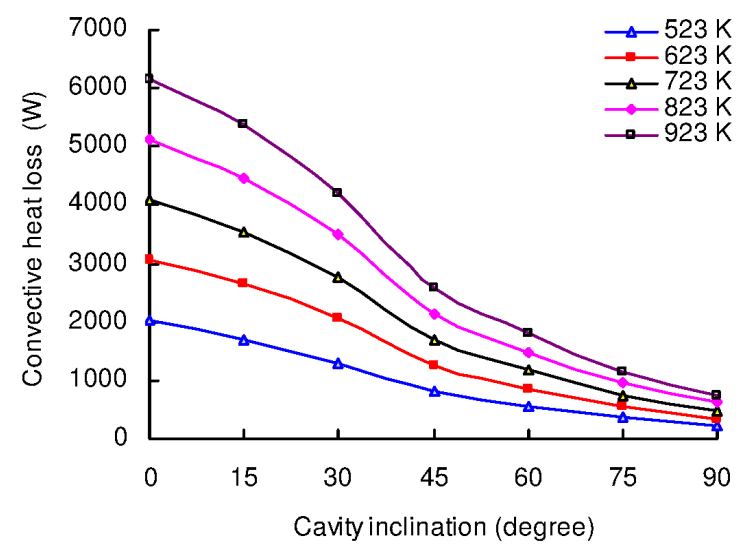

Figure 4. Variation of convective heat loss for cylindrical base cavity 

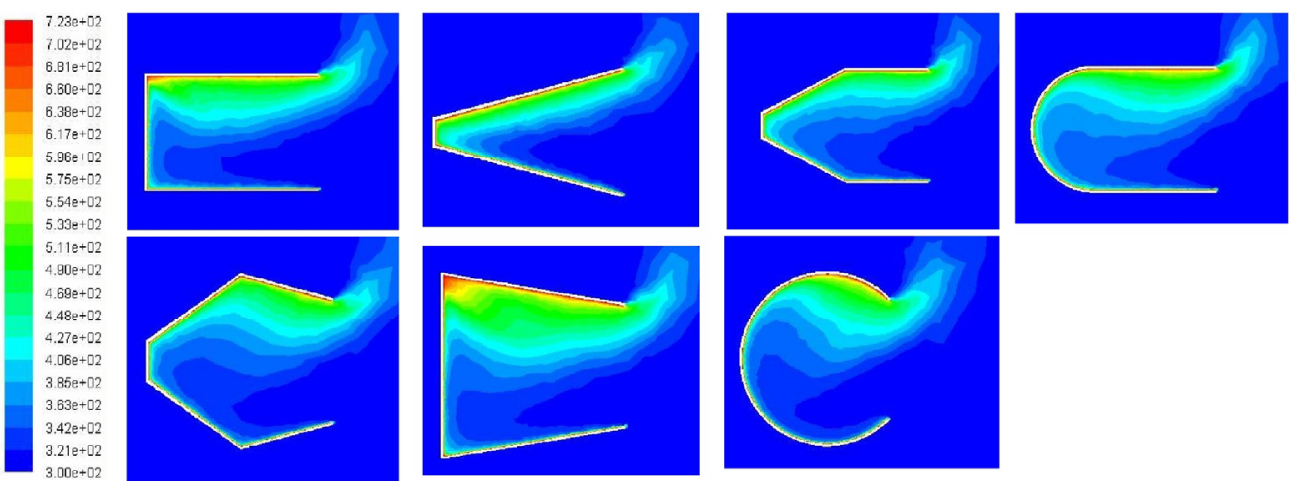

(a) $\theta=0^{\circ}$
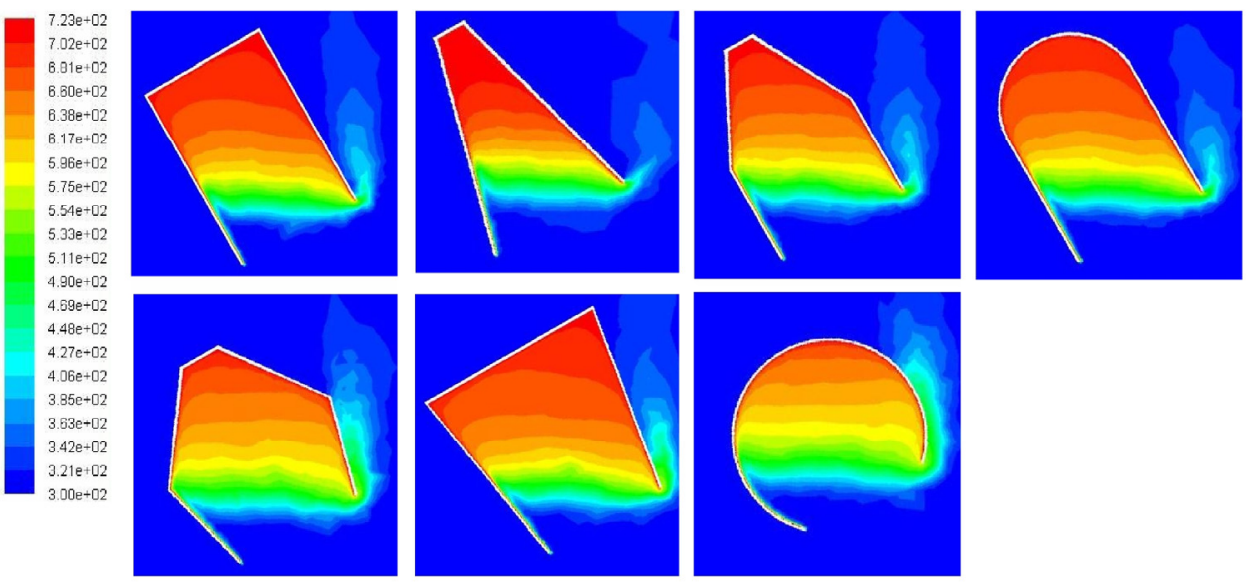

(b) $\theta=30^{\circ}$
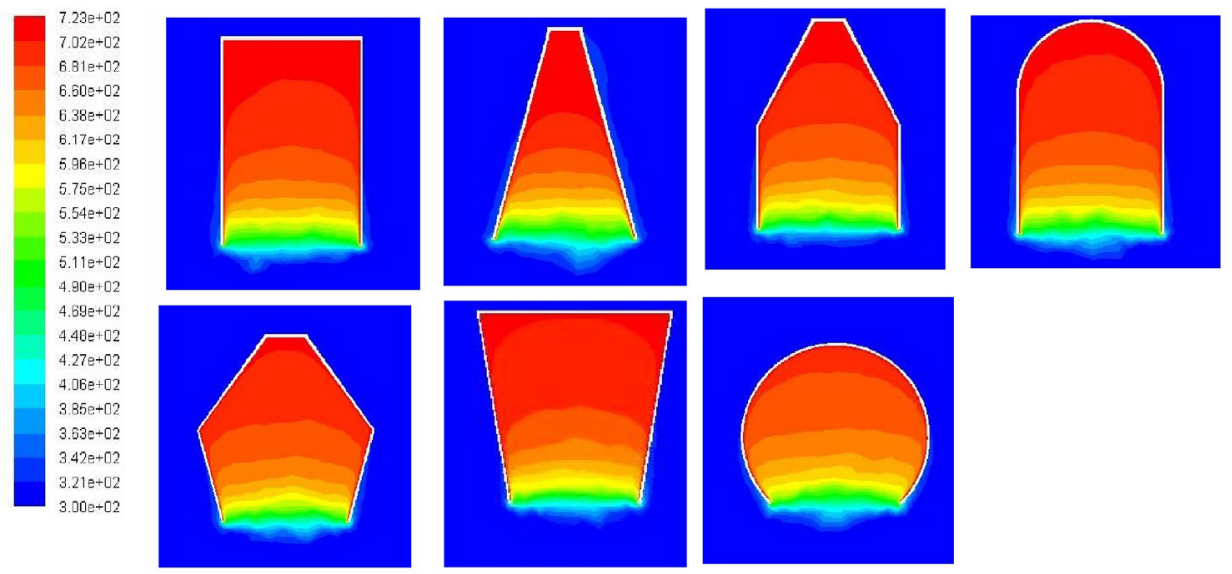

(c) $\theta=90^{\circ}$

Figure 5. Temperature contours of cavities at $T_{w}=723 \mathrm{~K}$

It is observed that, the maximum convection loss occurs at $0^{\circ}$ at all temperatures. With increase in inclination, the convection loss reduces to a minimum at $90^{\circ}$, as expected. According to Clausing (1981) a part of the cavity experiences stagnation condition and the boundary separating this area from the remaining part of the cavity can be approximated as a horizontal plane called as stagnation zone boundary. The part of the cavity above this plane is called as the stagnation zone while the below is called convective zone where strong convective air currents are observed. The increase in the inclination results in the increase in stagnant zone volume within the cavity and decrease in convective zone. Consequently, the internal wall area contributing to convective loss reduces, thereby reducing convective loss. 
In order to understand this effect, air temperature profile for different cavities are plotted for a typical temperature value of $723 \mathrm{~K}$ in Figure 5, (a) to (c) at different inclination angles. At $0^{\circ}$ cavity inclination (Figure 5a), the convective air occupies almost the complete volume of the cavity. As the cavity inclination increases from $0^{\circ}$ to $90^{\circ}$, the volume of high temperature stagnant air increases, the maximum being at $90^{\circ}$. Thus, the cavity area participating in convection decreases as the inclination increases and hence the convective heat loss decreases.

The variation of convective heat loss with respect to inclination is shown in Figure 6 (a) and (b). It can be seen that, for both cases, conical cavity has lower convective heat loss whereas spherical cavity has the highest convective heat loss.

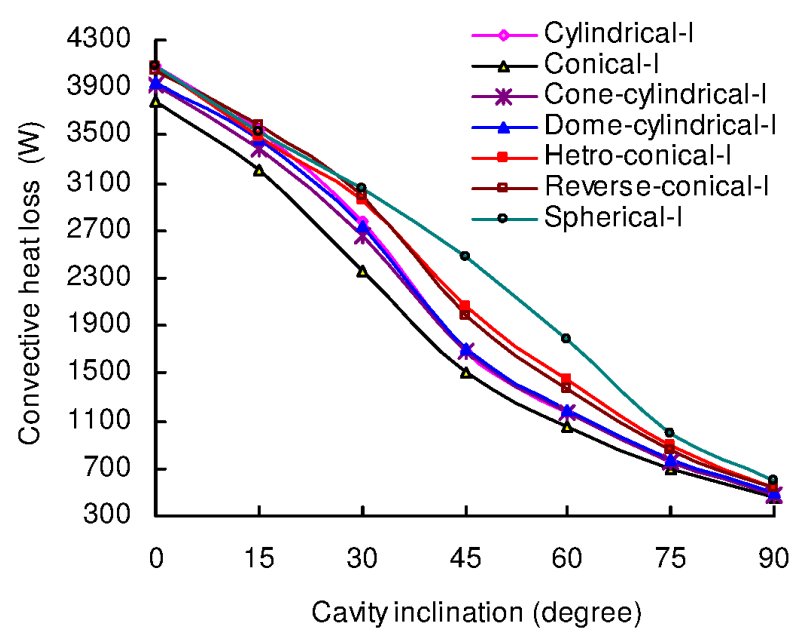

(a) Case I

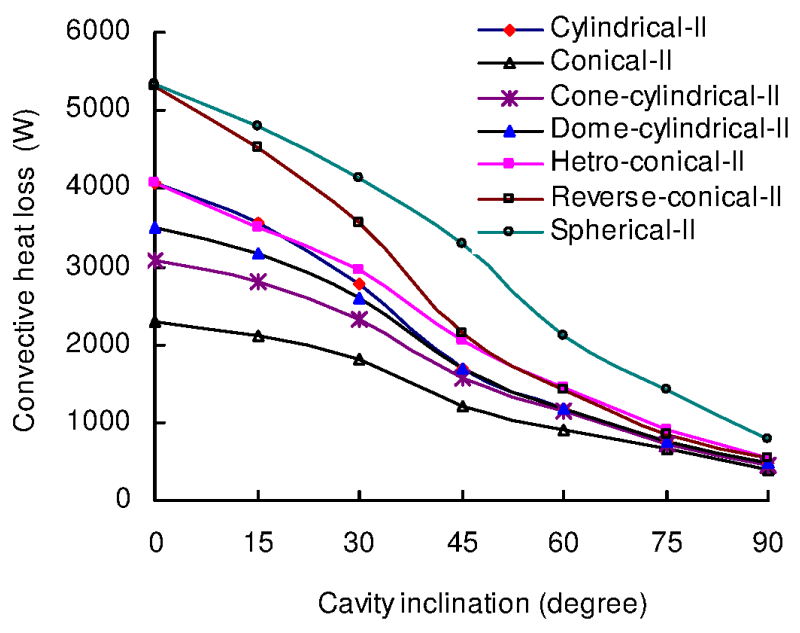

(b) Case II

Figure 6. Variation of convective heat loss

In order to identify the internal cavity area contributing to convective loss $\left(\mathrm{Q}_{\text {conv }}\right)$, zone boundary is calculated using Clausing's hypothesis. According to Clausing (1981) the boundary separating stagnation and convective zone can be approximated as a horizontal plane passing through the upper lip of the aperture. The cavity area participating in convective heat transfer is calculated using different approaches. In the first approach, active convective wall area $\left(\mathrm{A}_{\mathrm{cw}}\right)$ is considered. It is defined as the sum of internal wall areas of the cavity below zone boundary. Convective loss $\left(\mathrm{Q}_{\text {conv }}\right)$ from all types of cavities is plotted against $\mathrm{A}_{\mathrm{cw}}$ for a typical cavity wall temperature of $723 \mathrm{~K}$ and cavity inclination from $\theta=0^{\circ}$ to $90^{\circ}$ in Figure 7. It shows that convective loss is proportional to the convective wall area $\left(\mathrm{A}_{\mathrm{cw}}\right)$ despite the differences in shapes and size of the cavity with coefficient of correlation $\left(\mathrm{R}^{2}\right)=0.967$. It may be mentioned that, from the numerical calculations, $\mathrm{Q}_{\mathrm{conv}}$ is found 
to be finite at $\theta=90^{\circ}$ even if $A_{c w}$ is zero (consequence of zone boundary definition of Clausing, 1981) Thus $Q_{\text {conv }}$ cannot be estimated based on Clausing's approach. This is a limitation as far as $\mathrm{A}_{\mathrm{cw}}$ is concerned.

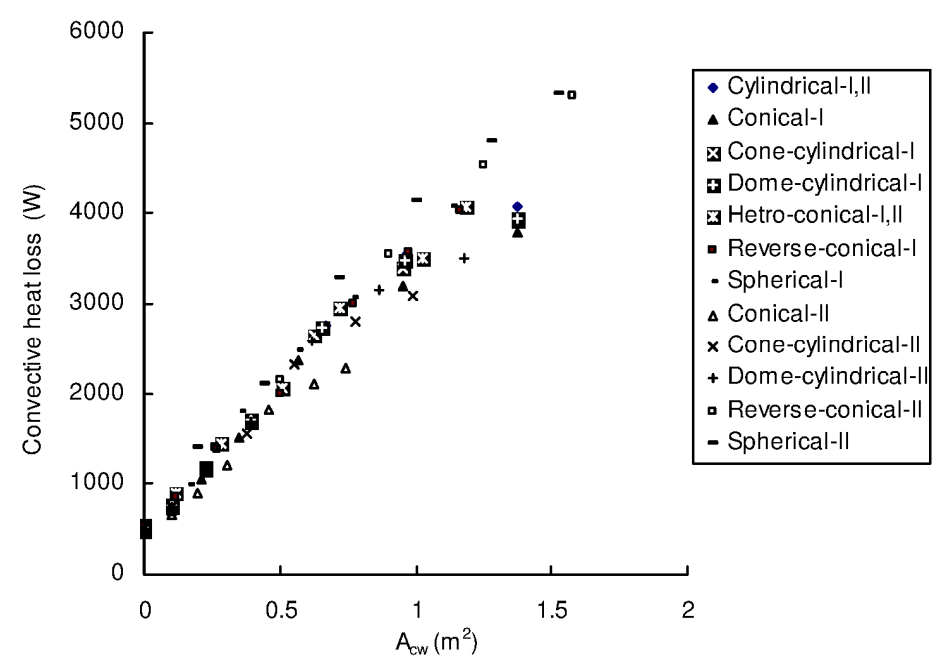

Figure 7. Variation of $\mathrm{Q}_{\text {conv }}$ with $\mathrm{A}_{\mathrm{cw}}$

In second approach, following Clausing et al. (1987), convective zone area $\left(\mathrm{A}_{\mathrm{cz}}\right)$ is calculated. $\mathrm{A}_{\mathrm{cz}}$ is defined as the sum of the $A_{c w}$ and the aperture area of the cavity $\left(A_{a p}\right)$. Figure 8 shows plot of convective loss with $A_{c z}$. With constant addition of aperture area in convective wall area $\left(A_{c w}\right), R^{2}$ remains unchanged but $Q_{\text {conv }}$ at $90^{\circ}$ can be calculated unlike $\mathrm{A}_{\mathrm{cw}}$.

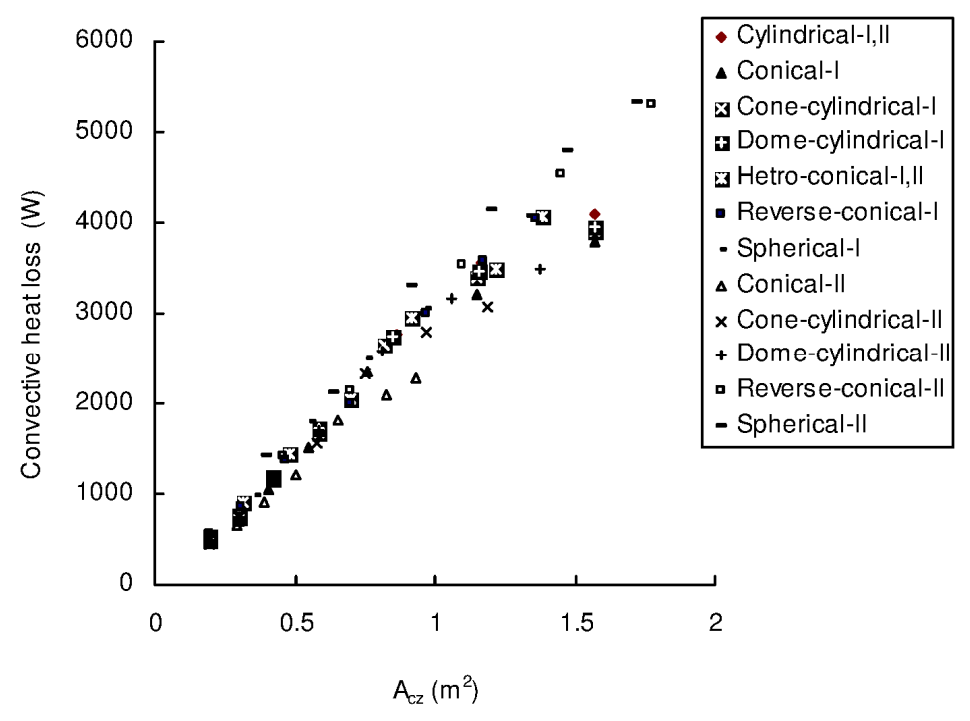

Figure 8. Variation of $\mathrm{Q}_{\mathrm{conv}}$ with $\mathrm{A}_{\mathrm{cz}}$

A better correlation is observed (Figure 9) if the $A_{c b}$ is used as basis. It is defined as the sum of $A_{c w}$ and $A_{b z}$, where $A_{b z}$ is the area of zone boundary separating stagnation and convective zone which varies with the cavity inclination. $A_{c b}$ is termed as modified convective zone area. It may be mentioned that $R^{2}$ value in this case becomes 0.987 which is higher than the previous two cases. Further, $\mathrm{Q}_{\text {conv }}$ at $90^{\circ}$ can also be calculated like $\mathrm{A}_{\mathrm{cz}}$. 


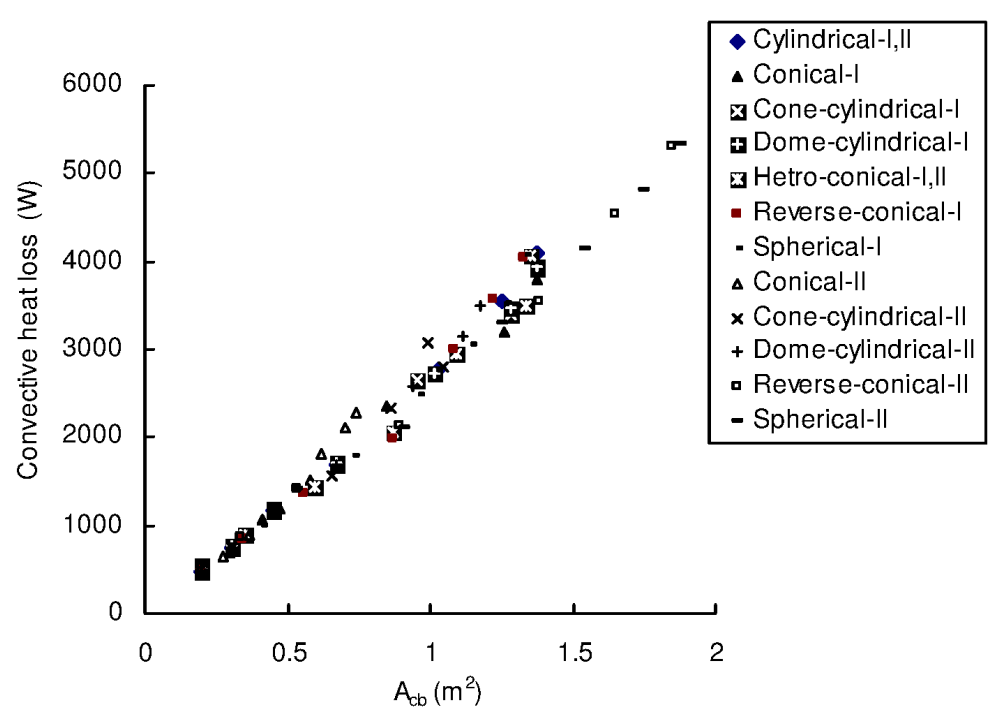

Figure 9. Variation of $\mathrm{Q}_{\text {conv }}$ with $\mathrm{A}_{\mathrm{cb}}$

The conventional way of defining convective heat transfer based on internal cavity surface area $\left(A_{w}\right)$ is also undertaken in the present work. Figure 10 shows a plot of $\mathrm{Q}_{\text {conv }}$ with $\mathrm{A}_{\mathrm{w}}$. It may be mentioned that (Figure 6 (a)), for the same value $A_{w}$, convective losses are different from one shape to another. Consequently correlation based on $A_{w}$ in predicting the convective loss would differ for these cavities, as seen in Figure 10. Thus, among the areas, $A_{c b}$ is a better parameter to correlate $Q_{\text {conv }}$. For clarity, different convective areas $\left(A_{c w}, A_{c z}\right.$ and $\left.A_{c b}\right)$ are shown in Figure A.1 (Appendix A) and their values for different cavities are presented in Table A.1.

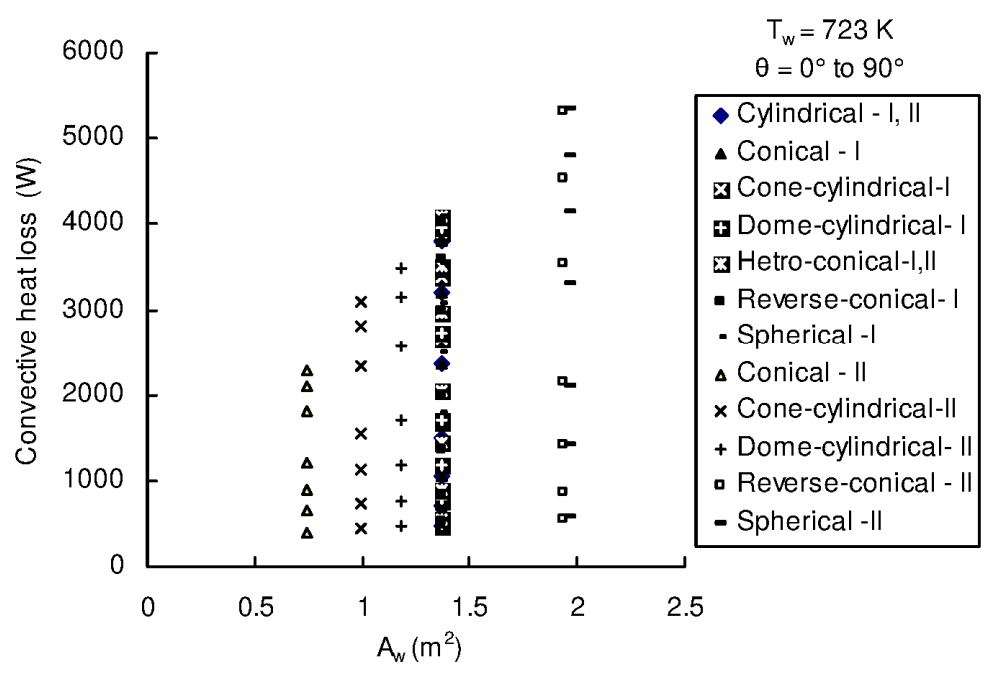

Figure 10. Variation of $\mathrm{Q}_{\text {conv }}$ with $\mathrm{A}_{\mathrm{w}}$

\subsection{Correlation Developed}

Generalized correlation for predicting the convective heat loss from cavities of all shapes and sizes has been developed. The approach adapted is as follows. From the numerically obtained values of the convective heat loss $\left(\mathrm{Q}_{\text {conv }}\right)$, the convective heat transfer coefficient $(\mathrm{h})$ is calculated as

$$
\mathrm{h}=\mathrm{Q}_{\text {conv }} /\left[\mathrm{A}_{\mathrm{cb}} \times\left(\mathrm{T}_{\mathrm{w}}-\mathrm{T}_{\mathrm{a}}\right)\right]
$$

where $T_{w}$ and $T_{a}$ are respectively the cavity wall temperature and ambient temperature. Nusselt number is calculated taking aperture diameter as the characteristics dimension. The properties of air are estimated at the mean temperature of $T_{w}$ and $T_{a}$. To study the effect of $T_{w}$ and $\theta$ on Nu, values of $\mathrm{Nu}$ are plotted against $T_{w}$ (523 
to $923 \mathrm{~K})$ and $\theta\left(0\right.$ to $\left.90^{\circ}\right)$ in Figure 11 (a) and (b) respectively.

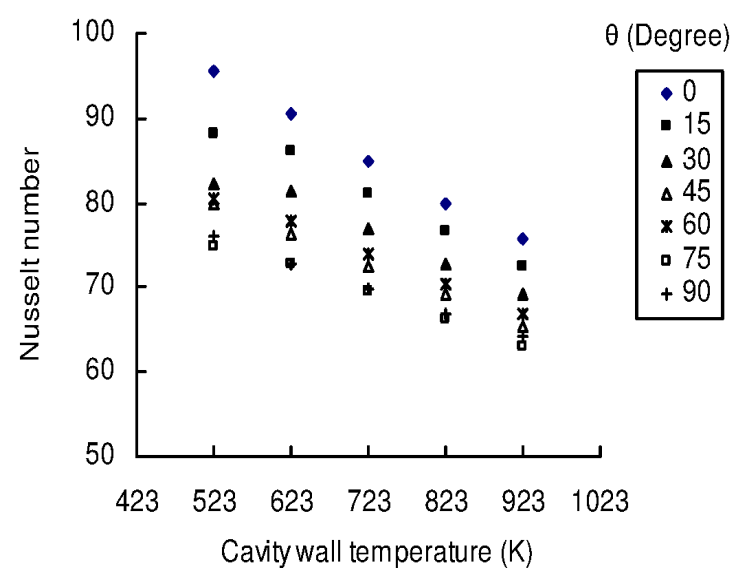

(a)

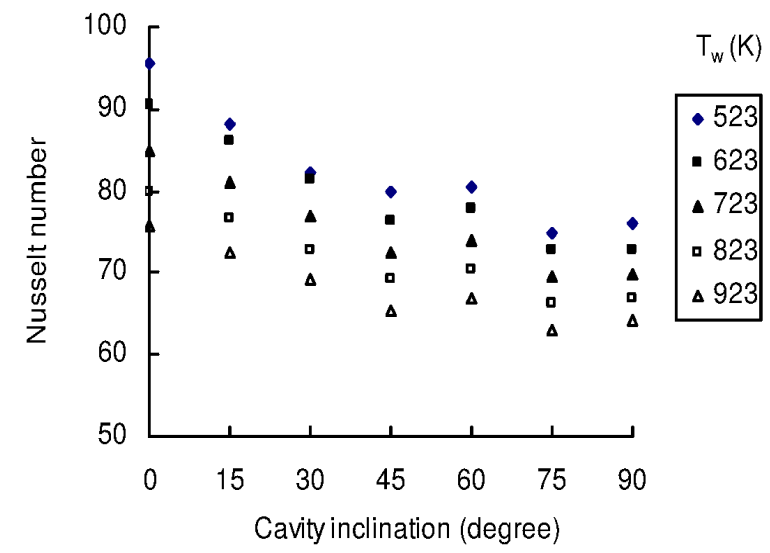

(b)

Figure 11. Nusselt number variation with wall temperature and inclination

Figure 11 (a) shows that the $\mathrm{Nu}$ varies with $\mathrm{T}_{\mathrm{w}}$ and this variation is between $16 \%$ (for $\theta=90^{\circ}$ ) and $21 \%$ (for $\theta=$ $\left.0^{\circ}\right)$. This variation could be attributed to the influence of variation in the air properties due to variation in the absolute temperature ratio $\left(\mathrm{T}_{\mathrm{w}} / \mathrm{T}_{\mathrm{a}}\right)$. Hence $\left(\mathrm{T}_{\mathrm{w}} / \mathrm{T}_{\mathrm{a}}\right)$ is taken as a parameter in the proposed correlation for $\mathrm{Nu}$ (Clausing et al., 1987). Figure 11(b) shows that $\mathrm{Nu}$ is also a function of $\theta$, hence the cavity inclination is accounted in the proposed correlation by the term $(1+\cos \theta)$ as the convective loss is found to be present at $\theta=$ $90^{\circ}$. Sendhilkumar and Reddy (2007) and Prakash et al. (2009) have also used $(1+\cos \theta)$ in their correlation.

The calculated values of $\mathrm{Nu}$ correlated with $\mathrm{Ra}, \mathrm{T}_{\mathrm{w}} / \mathrm{T}_{\mathrm{a}}$ and $(1+\cos \theta)$ is given by

$$
\mathrm{Nu}=0.122(\mathrm{Ra})^{0.31}\left(\mathrm{~T}_{\mathrm{w}} / \mathrm{T}_{\mathrm{a}}\right)^{0.066}(1+\cos \theta)^{0.38}
$$

for Rayleigh number between $2 \times 10^{8}$ and $6 \times 10^{8}$.

The parity plots between numerical and correlated Nusselt number are shown in Figure 12. It is observed that, proposed correlation correlates $91 \%$ of data within $\pm 11 \%, 99 \%$ of data within $\pm 16 \%$ and $100 \%$ of data within $\pm 19 \%$; the standard error being 0.06 .

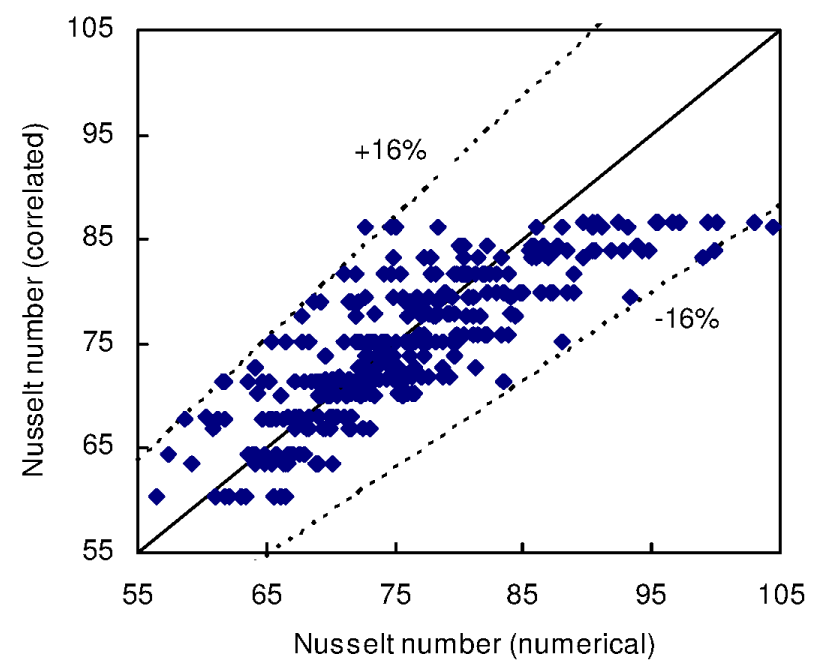

Figure 12. Parity plot for the correlation developed 
It may be noted that the correlation proposed by Sendhilkumar and Reddy (2007) is valid for hemispherical cavity and for Rayleigh number range $7 \times 10^{5}$ to $7 \times 10^{6}$. The correlation proposed by Prakash et al. (2009) is valid for cylindrical cavity with wind skirt and for Rayleigh number range $2.3 \times 10^{8}$ to $3.4 \times 10^{8}$. Sendhilkumar and Reddy (2007) have reported that coefficient of correlation is 0.97 with standard deviation of 0.168 . Prakash et al. (2009) have reported that the maximum of deviation of their correlation with experimental results is about $12 \%$. As opposed to these, proposed correlation (Equation 7) is valid for open cavity receivers of different shapes.

The validation of the present generalized correlation (Equation 7) has been carried out with experimental data of convective loss measurements reported by Le Quere et al. (1981) on cubical cavity having Rayleigh number in the range of proposed correlation $\left(\mathrm{Ra}=5.51 \times 10^{8}\right)$. The results are plotted in Figure 13 which shows good agreement between experimental data and the values calculated using present correlation.

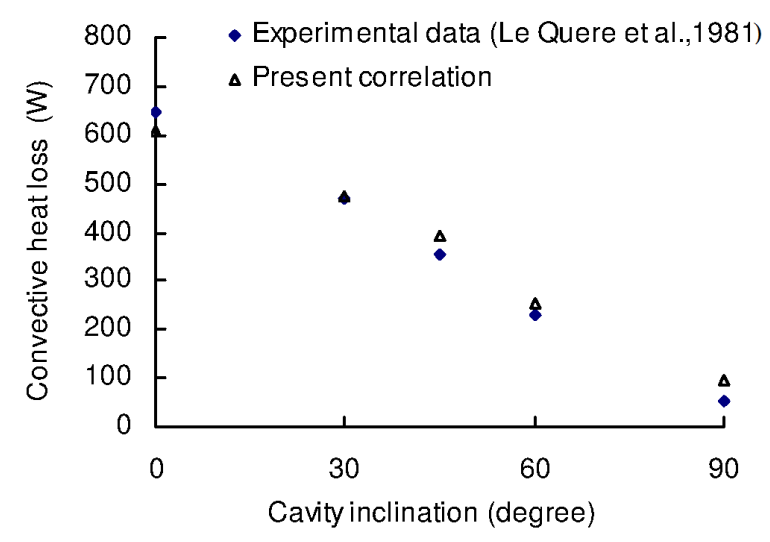

Figure 13. Validation of the present correlation with experimental data

\subsection{Radiative Heat Loss}

The radiative heat loss $\left(\mathrm{Q}_{\mathrm{rad}}\right)$ from various cavities under different temperature conditions has been calculated. It is observed that there is no inclination effect on radiative loss. $\mathrm{Q}_{\mathrm{rad}}$ calculated numerically for case I \& II are presented in Table 4.

Table 4. Radiative heat loss (W), $\mathrm{D}_{\mathrm{ap}}=0.5 \mathrm{~m}, \varepsilon=1$

\begin{tabular}{clccccc}
\hline Case & \multicolumn{1}{c}{ Cavity shape } & $523 \mathrm{~K}$ & $623 \mathrm{~K}$ & $723 \mathrm{~K}$ & $823 \mathrm{~K}$ & $923 \mathrm{~K}$ \\
\hline I & Cylindrical & 742 & 1585 & 2948 & 5011 & 7981 \\
& Hetro-Conical & 741 & 1584 & 2945 & 5006 & 7973 \\
& Conical & 740 & 1585 & 2948 & 5011 & 7980 \\
& Dome-cylindrical & 741 & 1585 & 2948 & 5012 & 7981 \\
& Cone-cylindrical & 741 & 1586 & 2947 & 5018 & 7980 \\
& Reverse-conical & 739 & 1585 & 2945 & 5006 & 7978 \\
& Spherical & 735 & 1568 & 2911 & 4937 & 7892 \\
\hline II & Cylindrical & 742 & 1585 & 2948 & 5011 & 7981 \\
& Hetro-Conical & 741 & 1584 & 2945 & 5006 & 7973 \\
& Conical & 741 & 1583 & 2944 & 5003 & 7968 \\
& Dome-cylindrical & 742 & 1585 & 2948 & 5011 & 7981 \\
& Cone-cylindrical & 740 & 1584 & 2947 & 5009 & 7977 \\
& Reverse-conical & 742 & 1585 & 2947 & 5010 & 7979 \\
& Spherical & 742 & 1586 & 2948 & 5011 & 7979 \\
\hline
\end{tabular}


It is seen that $\mathrm{Q}_{\mathrm{rad}}$ is independent of shape of cavities at any isothermal wall temperature. The factor $\mathrm{Q}_{\mathrm{rad}} / \mathrm{A}_{\text {ap }}$ is used to compare cavities with different shapes, sizes and aperture diameter and is plotted against $\left(\mathrm{T}_{\mathrm{w}}{ }^{4}-\mathrm{T}_{\mathrm{a}}^{4}\right)$ (Figure 14). It is seen that $\mathrm{Q}_{\mathrm{rad}}$ has strong dependence on the aperture area.

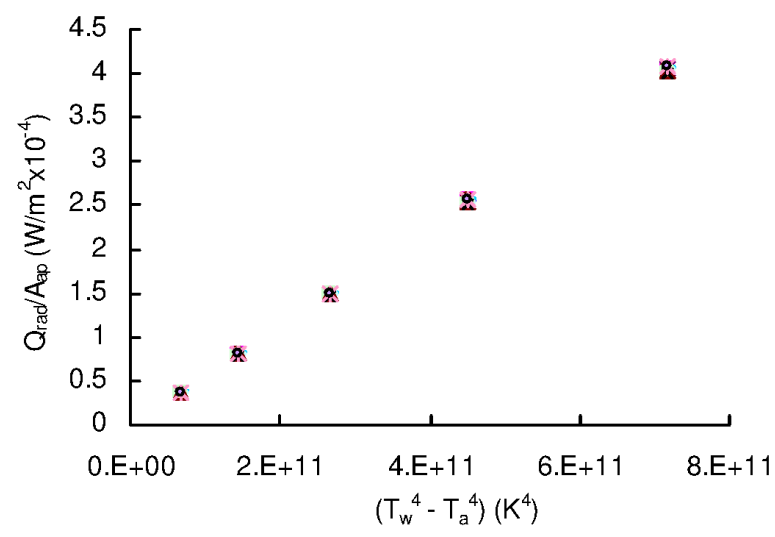

Figure 14. Variation of numerical radiative heat loss with $\left(\mathrm{T}_{\mathrm{w}}{ }^{4}-\mathrm{T}_{\mathrm{a}}{ }^{4}\right)$ for different shapes and sizes of the cavities

Radiative heat loss can also be calculated analytically as follows: The cavity surface is divided into a number of elemental surfaces; each element is having same or different values of temperature and emissivity (Holman, 1986). For each element it can be shown that

$$
\sigma \mathrm{T}_{\mathrm{w}, \mathrm{i}}{ }^{4}=\mathrm{J}_{\mathrm{i}}+\left(\frac{1-\varepsilon_{\mathrm{i}}}{\varepsilon_{\mathrm{i}}}\right) \sum_{\mathrm{j}=1}^{\mathrm{N}} \mathrm{F}_{\mathrm{ij}}\left(\mathrm{J}_{\mathrm{i}}-\mathrm{J}_{\mathrm{j}}\right)
$$

where $J_{i}$ is the radiosity, $F_{i j}$ is the fraction of radiant energy leaving surface $i$ and reaching surface $j$, $\varepsilon_{i}$ is the surface emissivity.

Net rate of heat transfer $(\mathrm{W})$ is given by,

$$
\mathrm{Q}_{\mathrm{rad}, \mathrm{i}}=\sum_{\mathrm{j}=1}^{\mathrm{N}} \mathrm{F}_{\mathrm{ij}}\left(\mathrm{J}_{\mathrm{i}}-\mathrm{J}_{\mathrm{j}}\right)
$$

If isothermal wall conditions exist inside the cavity and emissivity is constant for all elements of wall, then the entire inner cavity surface can be treated as single surface and surrounding enclosure as second surface. The radiative heat loss is given by (Wu \& Wen, 1978)

$$
\mathrm{Q}_{\mathrm{rad}}=\varepsilon_{\text {eff }} \sigma \mathrm{A}_{\mathrm{ap}}\left(\mathrm{T}_{\mathrm{w}^{4}}-\mathrm{T}_{\mathrm{a}^{4}}\right)
$$

where $\varepsilon_{\text {eff }}$ is effective emissivity of body and is given by,

$$
\varepsilon_{\text {eff }}=\frac{1}{1+\left(\frac{1-\varepsilon}{\varepsilon}\right) \frac{A_{\text {ap }}}{A_{w}}}
$$

It may be noted that Stefan-Bolzmann equation is based on the total surface area of a body emitting the radiation and its emissivity. On the other hand, Equation (10) is based on the aperture area of the receiver and the effective emissivity, which is a function of total surface area.

The results of analytical calculations have been compared with those of numerical scheme. A typical set of results for a cylindrical cavity is presented in Table 4 for various emissivity values. It is seen that there is a very good match between the two sets, as expected. One can therefore use analytical expression for estimating radiative loss for isothermal cavities in terms of aperture area and effective emissivity ( $\varepsilon_{\text {eff }}$ ). This has been found to be true for all other shapes as well. Thus, if the entire cavity surface is having uniform value of emissivity and temperature, then radiative heat loss can be calculated using Equation (10) in spite of differences in shapes of the cavities.

The present work can be used to determine convective losses Equation (7) and radiative losses Equation (10) 
from a downward facing cavity receiver of any of the shapes considered here and used with a paraboloid dish for industrial process heat or thermal power applications. This will help the designer to estimate receiver thermal loss coefficient which can be used with optical efficiency to determine the thermal performance of a dish-receiver system. To illustrate, an example of a $169 \mathrm{~m}^{2}$ paraboloid dish used at $350^{\circ} \mathrm{C}$ for industrial process heat is considered (Bhosale et al., 2008; Clique, www.clique.in). It has a cylindrical cavity receiver having aperture diameter of $0.5 \mathrm{~m}$ and depth $0.75 \mathrm{~m}$. For a value of beam normal radiation of $0.85 \mathrm{~kW} / \mathrm{m}^{2}$, the input power to the receiver is calculated to be about $113 \mathrm{~kW}$ based on the solidity of the dish, reflectivity of the mirror of the dish and the intercept factor. The convective and radiative heat losses are estimated, using the current numerical model for this receiver, to be about $3 \mathrm{~kW}$ and $1.6 \mathrm{~kW}$ respectively. The receiver loss coefficient therefore comes to be $0.084 \mathrm{~W} / \mathrm{m}^{2} \mathrm{~K}$ and the thermal losses amount to be about $4 \%$ of the input power.

\section{Conclusions}

The Numerical three dimensional combined study of the natural convection and radiation heat loss is carried out for open cavities with seven different shapes having isothermal wall temperatures 523 to $923 \mathrm{~K}$ and having constant emissivity. The effect of tilt angles on the heat loss is also investigated. The comparison of heat loss is carried out on common basis. Besides, based on the analysis, a generalized correlation for Nusselt number is proposed. This is valid for all geometries for $2 \times 10^{8} \leq \mathrm{Ra} \leq 6 \times 10^{8}$.

The following conclusions can be drawn from this study.

(1) Among the cavities investigated, the conical cavity yields the lowest convective loss, whereas the spherical cavity results in the highest convective loss. The dimensionless ratio of convective losses of different cavities with respect to conical cavity is in the range of 1.03 to 1.69 for case I type and 1.00 to 2.75 for case II type of cavity.

(2) Convective heat loss from cavities of different shapes and sizes can be characterized by using convective zone areas: $A_{c w}, A_{c z}$ and $A_{c b}$. Among these areas, $A_{c b}$ is found to be better parameter for the estimation of the convective loss, since it accounts for all apparent areas participating in convection at different inclination angles.

(3) Nusselt number correlation is developed which correlates $91 \%$ of data within $\pm 11 \%$ deviation, $99 \%$ of data within $\pm 16 \%$ deviation and $100 \%$ of data within $\pm 19 \%$ deviation. The ratio of radiative loss with aperture area $\left(\mathrm{Q}_{\mathrm{rad}} / \mathrm{A}_{\mathrm{ap}}\right)$ is found to be more or less constant (variation within $5 \%$ ) for all types of cavities and for $0 \leq \varepsilon \leq 1$. Thus radiative loss is dependent on aperture area and effective emissivity of cavity rather than the shape of the cavity from isothermal condition and can be calculated using analytical expression (Wu \& Wen, 1978).

\section{References}

Bhosale, S. J, Kedare, S. B., \& Nayak, J. K. (2008). Performance of Arun 160 concentrating solar collector installed at Latur for milk pasteurization. SESI Journal, 18(2), 22-31

Chandak, A. G., Somani, S. K., \& Dubey, D. (2009). Design, development of and testing of multieffect distiller/evaporator using Scheffler solar concentrator. Journal of Engineering Science and Technology, 4, 315-321.

Clausing, A. M. (1981). An analysis of convective losses from cavity solar central receivers. Solar Energy, 27, 295-300. http://dx.doi.org/10.1016/0038-092X(81)90062-1

Clausing, A. M. (1983). Convective losses from cavity solar receivers-comparisons between analytical predictions and experimental results. ASME Journal of Solar Energy Engineering, 105, 29-33, http://dx.doi.org/10.1115/1.3266342

Clausing, A. M., Waldvoge, J. M., \& Lister, L. D. (1987). Natural convectional from isothermal cubical cavities with a variety of side-facing apertures. ASME Journal of Heat Transfer, 109, 407-412. http://dx.doi.org/10.1115/1.3248095

D'Utruy, B., Blay, D., \& Coeytaux, M. (1978). The French CNRS 1 MW Solar Power Plant. In Proceedings of International Solar Energy Society Congress. New Delhi, 3, 1701-1705, New York, NY: Pergamon Press.

Fluent 6.3 User Guide. (2006).

Gray, D. D., \& Giorgini, A. (1976). The validity of the Boussinesq approximation for liquids and gases. International Journal of Heat and Mass Transfer, 19, 545-551. http://dx.doi.org/10.1016/0017-9310(76)90168-X 
Harris, J. A., \& Lenz, T. G. (1985). Thermal performance of solar concentrator/cavity receiver systems. Solar Energy, 34(2), 135-142. http://dx.doi.org/10.1016/0038-092X(85)90170-7

Holman, J. P. (1986). Heat Transfer (6th ed.). Singapore: McGraw-Hill.

Jiji, J. L. M. (2006). Heat Convection. Springer-Verlag

Kugath, D. A., Drenker, G., \& Koenig, A. A. (1979). Design and development of a paraboloidal dish solar collector for intermediate temperature service. In Proceedings of International Solar Energy Society, Silver Jubilee Congress, Atlanta, 1, pp. 449-453. New York: Pergamon Press.

Kumar, S., \& Reddy, K. S. (2007). Numerical investigation of natural convection heat loss in modified cavity receiver for fuzzy focal solar dish concentrator. Solar Energy, 81(7), 846-855. http://dx.doi.org/10.1016/j.solener.2006.11.008

Kumar, S., \& Reddy, K. S. (2008). Comparison of receivers for solar dish collector system. Energy Conversion and Management, 49, 812-819. http://dx.doi.org/10.1016/j.enconman.2007.07.026

Le Quere, P., Penot, F., \& Mirenayat, M. (1981) Experimental study of heat loss through natural convection from an isothermal cubic open cavity. In Proceedings DOE/SERI/SNLL Workshop on Convective Losses from Solar Receivers. Sandia Laboratory Report, SAND81-8014, Livermore, California.

Leibfried, U., \& Ortjohann J. (1995). Convective heat loss from upward and downward-facing cavity solar receivers: measurements and calculations. ASME Journal of Solar Energy Engineering, 117, 75-84. http://dx.doi.org/10.1115/1.2870873

Lezhebokov, A. I., Sokolova, Yu. B., \& Trukhov, V. S. (1986). Heat losses from a receiver of concentrated radiation in a solar energy unit with a thermodynamic transducer. Geliotekhnika (Applied Solar Energy), 22(2): 34-38.

Ma, R. Y. (1993). Wind effects on convective heat loss from a cavity receiver for parabolic concentrating solar collector. Contractor Report, Sandia National Laboratories, SAND92-7293, Albuquerque, New Mexico.

McDonald, C. G. (1995). Heat loss from an open cavity. Sandia National Laboratories Report, SAND95-2939.

Melchior, E. (1989). Receiver concepts and design-construction and tests of components. In M. Becker, \& M. Bohmer, (Eds.), GAST (The Gas Cooled Solar Tower Technology Program). Springer-Verlag, Berlin. http://dx.doi.org/10.1007/978-3-642-83559-9_14

Paitoonsurikarn, S., \& Lovegrove, K. (2002). Numerical investigation of natural convection loss in cavity-type solar receivers. In Proceedings of Solar 2002, ANZSES Annual Conference. Newcastle, Australia.

Paitoonsurikarn, S., \& Lovegrove, K. (2003). On the study of convection loss from open cavity receivers in solar paraboloidal dish application. In Proceedings of Solar 2003, ANZSES Annual Conference. Melbourne, Australia.

Paitoonsurikarn, S., \& Lovegrove, K. (2006). A new correlation for predicting the free convection loss from solar dish concentrating receivers. In Proceedings of Solar 2006: Clean Energy?-Can Do! ANZSES 2006, Canberra, Australia.

Paitoonsurikarn, S., Taumoefolau, T., \& Lovegrove, K. (2004). Estimation of Convection Loss from Paraboloidal Dish Cavity Receivers. In Proceedings of Solar 2004: Life, the Universe and Renewables, 42nd Annual Conference of the Australian and New Zealand Solar Energy Society, Perth, Australia.

Perez-Rabago, C. A., Marcos, M. J., Romero, M., \& Estrada, C. A. (2008). Heat transfer in a conical cavity calorimeter for measuring thermal power of a point focus concentrator. Solar Energy, 80, 1434-1442. http://dx.doi.org/10.1016/j.solener.2006.03.006

Prakash, M., Kedare, S. B., \& Nayak, J. K. (2009). Investigations on heat losses from a solar cavity receiver. Solar Energy, 83, 157-170. http://dx.doi.org/10.1016/j.solener.2008.07.011

Prakash, M., Kedare, S.B., \& Nayak J.K. (2010). Determination of stagnation and convective zones in a solar cavity receiver. International Journal of Thermal Sciences, 49, 680-691. http://dx.doi.org/10.1016/j.ijthermalsci.2009.06.015

Private communications to Clique (www.clique.in).

Reddy, K. S., \& Kumar, S. (2008). Combined laminar natural convection and surface radiation heat transfer in a modified cavity receiver of solar parabolic dish. International Journal of Thermal Sciences, 47, 1647-1657. http://dx.doi.org/10.1016/j.ijthermalsci.2007.12.001 
Reddy, K. S., \& Kumar, S. (2009). An improved model for natural convection heat loss from modified cavity receiver of solar dish concentrator. Solar Energy, 83, 1884-1892. http://dx.doi.org/10.1016/j.solener.2009.07.001

Ryu, S., \& Seo, T. (2000). Estimation of heat losses from the receivers for solar energy collecting system. KSME International Journal, 14(12), 1403-1411.

Sardeshpande, V. R., Chandak, A. G., \& Pillai, I. R. (2011). Procedure for thermal performance evaluation of steam generating point-focus solar concentrator. Solar Energy, 85, 1390-1398. http://dx.doi.org/10.1016/j.solener.2011.03.018

Seo, T., Ryu, S., \& Kang, Y. (2003). Heat losses from the receivers of multifaceted parabolic solar energy collecting system. KSME International Journal, 17(8), 1185-1195.

Siebers, D. L., \& Kraabel, J, S. (1984). Estimating convective losses from solar central receivers. Sandia Report, SAND84-8717, UC-62c, Printed in April 1984.

Stine, W. B., \& McDonald, C. G. (1988). Cavity receiver heat loss measurements. In Proceedings of ASME Solar Energy Division Conference. Denver, Colorado.

Stine, W. B., \& McDonald, C. G. (1989). Cavity receiver convective heat loss. In Proceedings of International Solar Energy Society Solar World Congress. September, 1989, Kobe, Japan, vol. 2, pp. 1318-1322. Oxford: Pergamon Press.

Taumoefolau, T., \& Lovegrove, K. (2002). An experimental study of natural convection heat loss from a solar concentrator cavity receiver at varying orientation. In Proceedings of Solar 2002, ANZSES Annual Conference. Newcastle, Australia.

Taumoefolau, T., Paitoonsurikarn, S., Hughes, G., \& Lovegrove, K. (2004). Experimental investigation of natural convection heat loss from a model solar concentrator cavity receiver. ASME Journal of Solar Energy Engineering, 126, 801-807. http://dx.doi.org/10.1115/1.1687403

Umarov, Ya. I., Fattakhov, A. A., Umarov, A. G., Trukhov, V. S., Tursunbaev, I. A., Sokolova, Yu. B., \& Gaziev, Yu. Kh. (1983). Heat loss in a cavity-type solar collector. Geliotekhnika (Applied Solar Energy), 19(3), 43-47.

Williams, O. M. (1980). Design and cost analysis for an ammonia-based solar thermochemical cavity absorber. Solar Energy, 24, 255-263. http://dx.doi.org/10.1016/0038-092X(80)90482-X

Wu, Y. C., \& Wen, L. C. (1978). Solar receiver performance of point focusing collector system. ASME Winter Annual Meeting, San Franciso, CA. 


\section{Appendix A}

For a cavity at any inclination the horizontal plane passing through the upper point (p) of the aperture gives separation zone boundary as shown in Figure A.1 (Clausing, 1981). This separation boundary divides the cavity inner area into two zones: The area above separation boundary is known as stagnation zone while the area below it is referred to as convective zone. It may be noted from Figure A1 that

$$
\mathrm{A}_{\mathrm{cw}}=\mathrm{A}_{1}+\mathrm{A}_{2}
$$

where $A_{1}$ is the inner area of back wall of the cavity below separation zone boundary and $A_{2}$ is the inner area of the lateral surfaces of the cavity below separation zone boundary.

$$
\mathrm{A}_{\mathrm{cz}}=\mathrm{A}_{\mathrm{cw}}+\mathrm{A}_{\mathrm{ap}}
$$

and

$$
\mathrm{A}_{\mathrm{cb}}=\mathrm{A}_{\mathrm{cw}}+\mathrm{A}_{\mathrm{bz}}
$$

where $A_{a p}$ is the cavity aperture area, $A_{b z}$ is the area of zone boundary separating stagnation and convective zone. $A_{w}$ (not shown in Figure A1) is the internal surface area of the entire cavity.

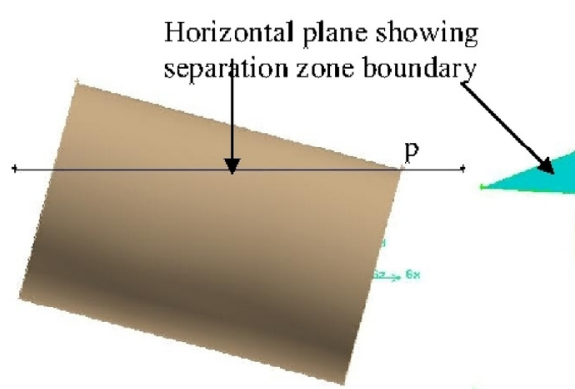

(a)

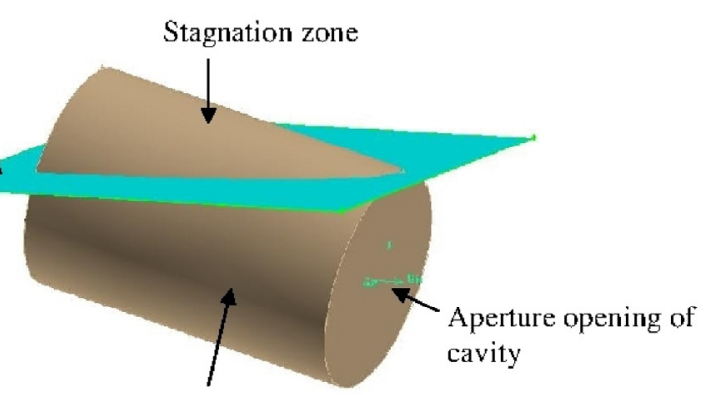

(b) Convective zone

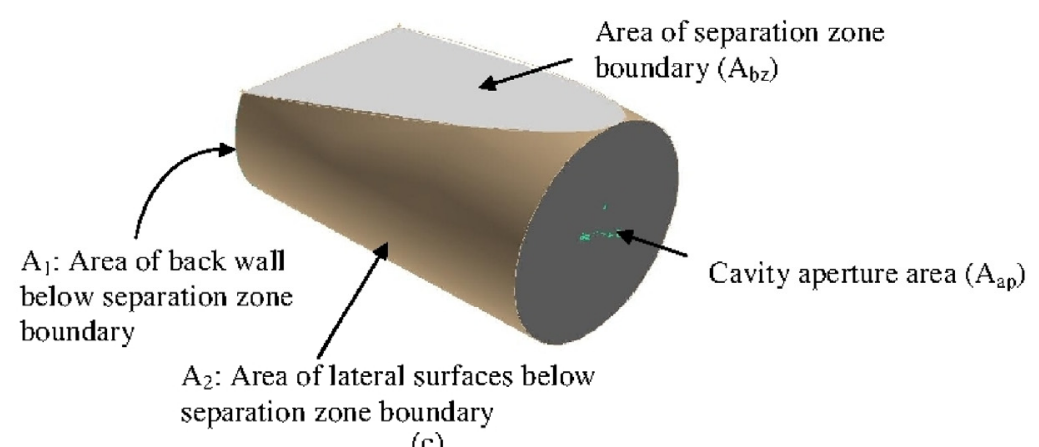

(c)

Figure A1. Definition of different convective zone areas 
Table A1. Values of the different areas used in the present work

\begin{tabular}{|c|c|c|c|c|c|c|c|c|c|}
\hline $\begin{array}{l}\text { Cavity } \\
\text { shape }\end{array}$ & Case & $\begin{array}{c}\text { Area } \\
\left(\mathrm{m}^{2}\right)\end{array}$ & $0^{\circ}$ & $15^{\circ}$ & $30^{\circ}$ & $45^{\circ}$ & $60^{\circ}$ & $75^{\circ}$ & $90^{\circ}$ \\
\hline \multirow{4}{*}{ Cylindrical } & \multirow{4}{*}{ I, II } & $\mathrm{A}_{\mathrm{cw}}$ & 1.374 & 0.9688 & 0.667 & 0.392 & 0.2267 & 0.1052 & 0 \\
\hline & & $\mathrm{A}_{\mathrm{cb}}$ & 1.374 & 1.2539 & 1.0283 & 0.6696 & 0.4534 & 0.3084 & 0.1963 \\
\hline & & $\mathrm{A}_{\mathrm{cz}}$ & 1.5703 & 1.1651 & 0.8633 & 0.5883 & 0.423 & 0.3015 & 0.1963 \\
\hline & & $\mathrm{A}_{\mathrm{w}}$ & 1.374 & 1.374 & 1.374 & 1.374 & 1.374 & 1.374 & 1.374 \\
\hline \multirow{8}{*}{ Conical } & \multirow{4}{*}{ I } & $\mathrm{A}_{\mathrm{cw}}$ & 1.374 & 0.9518 & 0.5642 & 0.3517 & 0.2128 & 0.1023 & 0 \\
\hline & & $\mathrm{A}_{\mathrm{cb}}$ & 1.374 & 1.2599 & 0.848 & 0.5814 & 0.4158 & 0.2953 & 0.1963 \\
\hline & & $\mathrm{A}_{\mathrm{cz}}$ & 1.5703 & 1.1481 & 0.7605 & 0.548 & 0.4091 & 0.2986 & 0.1963 \\
\hline & & $\mathrm{A}_{\mathrm{w}}$ & 1.374 & 1.374 & 1.374 & 1.374 & 1.374 & 1.374 & 1.374 \\
\hline & \multirow{4}{*}{ II } & $\mathrm{A}_{\mathrm{cw}}$ & 0.739 & 0.628 & 0.4557 & 0.3042 & 0.196 & 0.0999 & 0 \\
\hline & & $\mathrm{A}_{\mathrm{cb}}$ & 0.739 & 0.644 & 0.6186 & 0.471 & 0.3642 & 0.2765 & 0.1963 \\
\hline & & $\mathrm{A}_{\mathrm{cz}}$ & 0.9353 & 0.8243 & 0.652 & 0.5005 & 0.3923 & 0.2962 & 0.1963 \\
\hline & & $\mathrm{A}_{\mathrm{w}}$ & 0.739 & 0.739 & 0.739 & 0.739 & 0.739 & 0.739 & 0.739 \\
\hline \multirow{8}{*}{$\begin{array}{l}\text { Cone- } \\
\text { cylindrical }\end{array}$} & \multirow{4}{*}{ I } & $\mathrm{A}_{\mathrm{cw}}$ & 1.374 & 0.9546 & 0.6234 & 0.392 & 0.2267 & 0.1052 & 0 \\
\hline & & $\mathrm{A}_{\mathrm{cb}}$ & 1.374 & 1.2792 & 0.956 & 0.6696 & 0.4534 & 0.3084 & 0.1963 \\
\hline & & $\mathrm{A}_{\mathrm{cz}}$ & 1.5703 & 1.1509 & 0.8197 & 0.5883 & 0.423 & 0.3015 & 0.1963 \\
\hline & & $\mathrm{A}_{\mathrm{w}}$ & 1.374 & 1.374 & 1.374 & 1.374 & 1.374 & 1.374 & 1.374 \\
\hline & \multirow{4}{*}{ II } & $\mathrm{A}_{\mathrm{cw}}$ & 0.989 & 0.7755 & 0.555 & 0.38 & 0.2267 & 0.1052 & 0 \\
\hline & & $\mathrm{A}_{\mathrm{cb}}$ & 0.989 & 1.0436 & 0.8614 & 0.6576 & 0.4534 & 0.3084 & 0.1963 \\
\hline & & $\mathrm{A}_{\mathrm{cz}}$ & 1.1853 & 0.9718 & 0.7513 & 0.5763 & 0.423 & 0.3015 & 0.1963 \\
\hline & & $\mathrm{A}_{\mathrm{w}}$ & 0.989 & 0.989 & 0.989 & 0.989 & 0.989 & 0.989 & 0.989 \\
\hline \multirow{8}{*}{$\begin{array}{l}\text { Dome- } \\
\text { cylindrical }\end{array}$} & \multirow{4}{*}{ I } & $\mathrm{A}_{\mathrm{cw}}$ & 1.374 & 0.9587 & 0.6536 & 0.392 & 0.2267 & 0.1052 & 0 \\
\hline & & $\mathrm{A}_{\mathrm{cb}}$ & 1.374 & 1.2793 & 1.0151 & 0.6696 & 0.4534 & 0.3084 & 0.1963 \\
\hline & & $\mathrm{A}_{\mathrm{cz}}$ & 1.5703 & 1.155 & 0.8499 & 0.5883 & 0.423 & 0.3015 & 0.1963 \\
\hline & & $\mathrm{A}_{\mathrm{w}}$ & 1.374 & 1.374 & 1.374 & 1.374 & 1.374 & 1.374 & 1.374 \\
\hline & \multirow{4}{*}{ II } & $\mathrm{A}_{\mathrm{cw}}$ & 1.178 & 0.8629 & 0.6188 & 0.392 & 0.2267 & 0.1052 & 0 \\
\hline & & $\mathrm{A}_{\mathrm{cb}}$ & 1.178 & 1.1182 & 0.9405 & 0.6696 & 0.4534 & 0.3084 & 0.1963 \\
\hline & & $\mathrm{A}_{\mathrm{cz}}$ & 1.3743 & 1.0592 & 0.8151 & 0.5883 & 0.423 & 0.3015 & 0.1963 \\
\hline & & $\mathrm{A}_{\mathrm{w}}$ & 1.178 & 1.178 & 1.178 & 1.178 & 1.178 & 1.178 & 1.178 \\
\hline \multirow{4}{*}{$\begin{array}{l}\text { Hetro- } \\
\text { conical }\end{array}$} & \multirow{4}{*}{ I, II } & $\mathrm{A}_{\mathrm{cw}}$ & 1.188 & 1.0253 & 0.7231 & 0.5056 & 0.2828 & 0.1195 & 0 \\
\hline & & $\mathrm{A}_{\mathrm{cb}}$ & 1.3492 & 1.3347 & 1.0889 & 0.8672 & 0.5957 & 0.3546 & 0.1963 \\
\hline & & $\mathrm{A}_{\mathrm{cz}}$ & 1.3843 & 1.2216 & 0.9194 & 0.7019 & 0.4791 & 0.3158 & 0.1963 \\
\hline & & $\mathrm{A}_{\mathrm{w}}$ & 1.374 & 1.374 & 1.374 & 1.374 & 1.374 & 1.374 & 1.374 \\
\hline \multirow{8}{*}{$\begin{array}{l}\text { Reverse- } \\
\text { conical }\end{array}$} & \multirow{4}{*}{ I } & $\mathrm{A}_{\mathrm{cw}}$ & 1.163 & 0.9781 & 0.7734 & 0.5 & 0.2683 & 0.1146 & 0 \\
\hline & & $\mathrm{A}_{\mathrm{cb}}$ & 1.3254 & 1.2176 & 1.0814 & 0.8721 & 0.554 & 0.3404 & 0.1963 \\
\hline & & $\mathrm{A}_{\mathrm{cz}}$ & 1.3593 & 1.1744 & 0.9697 & 0.6963 & 0.4646 & 0.3109 & 0.1963 \\
\hline & & $\mathrm{A}_{\mathrm{w}}$ & 1.374 & 1.374 & 1.374 & 1.374 & 1.374 & 1.374 & 1.374 \\
\hline & \multirow{4}{*}{ II } & $\mathrm{A}_{\mathrm{cw}}$ & 1.581 & 1.2525 & 0.8989 & 0.5014 & 0.261 & 0.1129 & 0 \\
\hline & & $\mathrm{A}_{\mathrm{cb}}$ & 1.8489 & 1.6508 & 1.3789 & 0.8956 & 0.5372 & 0.3354 & 0.1963 \\
\hline & & $\mathrm{A}_{\mathrm{cz}}$ & 1.7773 & 1.4488 & 1.0952 & 0.6977 & 0.4573 & 0.3092 & 0.1963 \\
\hline & & $\mathrm{A}_{\mathrm{w}}$ & 1.934 & 1.934 & 1.934 & 1.934 & 1.934 & 1.934 & 1.934 \\
\hline \multirow{8}{*}{ Spherical } & \multirow{4}{*}{ I } & $\mathrm{A}_{\mathrm{cw}}$ & 1.1324 & 0.9657 & 0.7722 & 0.5654 & 0.3585 & 0.1163 & 0 \\
\hline & & $\mathrm{A}_{\mathrm{cb}}$ & 1.3364 & 1.2692 & 1.1476 & 0.9654 & 0.73 & 0.4132 & 0.1963 \\
\hline & & $\mathrm{A}_{\mathrm{cz}}$ & 1.3287 & 1.162 & 0.9685 & 0.7617 & 0.5548 & 0.3126 & 0.1963 \\
\hline & & $\mathrm{A}_{\mathrm{w}}$ & 1.374 & 1.374 & 1.374 & 1.374 & 1.374 & 1.374 & 1.374 \\
\hline & \multirow{4}{*}{ II } & $\mathrm{A}_{\mathrm{cw}}$ & 1.529 & 1.28 & 1 & 0.7193 & 0.4446 & 0.1993 & 0 \\
\hline & & $\mathrm{A}_{\mathrm{cb}}$ & 1.8789 & 1.75 & 1.5385 & 1.2545 & 0.9063 & 0.5369 & 0.1963 \\
\hline & & $\mathrm{A}_{\mathrm{cz}}$ & 1.7253 & 1.4763 & 1.1963 & 0.9156 & 0.6409 & 0.3956 & 0.1963 \\
\hline & & $\mathrm{A}_{\mathrm{w}}$ & 1.967 & 1.967 & 1.967 & 1.967 & 1.967 & 1.967 & 1.967 \\
\hline
\end{tabular}




\section{Nomenclature}

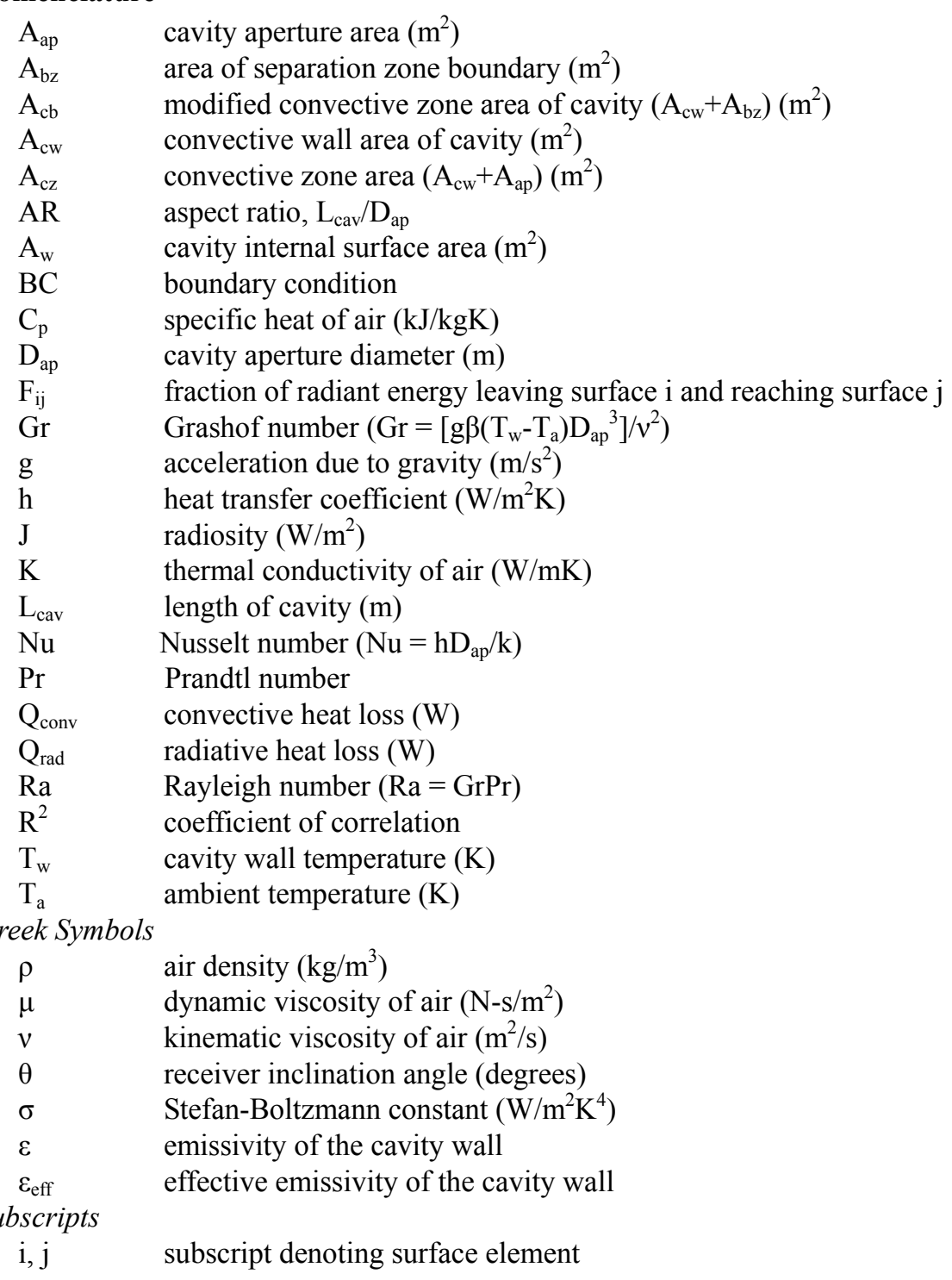

